\title{
O Climatério e suas Implicações na Sexualidade
}

\section{Climacteric Period and Its Implications in Sexuality}

\author{
Sibely dos Santos ${ }^{1}$ \\ Claudia Moreira de Lima ${ }^{2}$ \\ Jefferson Tennesse da Silva Vicente ${ }^{3}$ \\ Grasiela Cristina Silva Botelho Silvestre ${ }^{4}$ \\ Hilton Giovani Neves ${ }^{5}$
}

Sue Ellen Ferreira Modesto Rey de Figueiredo ${ }^{6}$

\begin{abstract}
${ }^{1}$ Enfermeira Assistencial no Hospital Municipal de Várzea Grande. Várzea Grande, MT, Brasil. E-mail. sibelly36@hotmail.com.
${ }^{2}$ Enfermeira. Mestranda no Programa Ambiente e Saúde pela Universidade de Cuiabá (UNIC). Nova Olímpia, MT, Brasil. E-mail: cml_claudiamoreira@hotmail.com. Autor Correspondente.

${ }^{3}$ Enfermeiro. Mestrando no Programa Ambiente e Saúde pela Universidade de Cuiabá (UNIC). Cuiabá, MT, Brasil. E-mail: enf.jefftennesse@gmail.com. ${ }^{4}$ Enfermeira. Mestranda no Programa Ambiente e Saúde pela Universidade de Cuiabá (UNIC). Docente Assistente no Departamento de Enfermagem da Universidade do Estado de Mato Grosso (UNEMAT). Diamantino, MT, Brasil. E-mail: enf.grasielabotelho@gmail.com.

${ }^{5}$ Enfermeiro. Mestre. Docente Assistente no Departamento de Enfermagem da Universidade do Estado de Mato Grosso (UNEMAT). Cuiabá, MT, Brasil. E-mail: hgneves@terra.com.br.
\end{abstract}

${ }^{6}$ Psicóloga. Doutora em Oncologia pelo Hospital A.C. Camargo da Fundação Antônio Prudente. Docente do Programa de Pós-Graduação Scrito Sensu em Ambiente e Saúde da Universidade de Cuiabá (UNIC). Cuiabá, MT, Brasil. E-mail: suemodesto@hotmail.com. 


\section{Resumo}

Objetiva-se descrever como mulheres vivenciam sua sexualidade durante o período do climatério. Trata-se de um estudo descritivo de abordagem qualitativa, com realização de entrevistas com questionário semi estruturado, realizado em um Centro de Saúde localizado no município de Tangará da Serra - MT. Os participantes foram 10 mulheres na faixa etária de 48 a 58 anos. Do processo de análise temática dos relatos obtidos, surgiram 3 categorias: Mudanças mais significativas durante o climatério, Fatores que interferem na sexualidade e Percepção da mulher de si mesma. Os resultados apontam para alguns agrupamentos de unidade de registro os quais revelam que a maioria das participantes perceberam diminuição de sua atividade sexual. Quanto aos fatores que influenciam a sexualidade, os mais destacados foram o envelhecimento e o relacionamento conjugal. No que tange ao exercício da sexualidade os fatores se restringiram as alterações fisiológicas provocadas pelo climatério, e em relação à percepção destas mulheres sobre si, a maioria das participantes evidenciou uma percepção positiva sobre si mesma. Conclui-se que é importante a elaboração de ações de saúde voltadas para a mulher no climatério a fim de divulgar informações para maior compreensão acerca da temática e assim viver a sexualidade de forma saudável por todos em qualquer idade/período.

Palavras-chave: Sexualidade; Climatério; Saúde da Mulher.

\section{Abstract}

It aims to describe how women experience their sexuality during the climacteric period. It is a descriptive study with a qualitative approach, with semi structured interviews conducted at a Health Center located in the city of Tangará da Serra - MT. The participants were 10 women in the age group from 48 to 58 years-old. From the thematic analysis process of the obtained reports, three categories emerged: Most significant changes during the climacteric period, Factors that interfere in sexuality and Perception of the woman about herself. The results point to some groupings of the recording unit which reveal that the participants' majority perceived a decrease in their sexual activity. As for the factors that influence sexuality, the most outstanding ones were aging and the marital relationship. Regarding the exercise of sexuality, the factors were restricted to the physiological changes caused by the climacteric period, and in relation to the perception of these women about themselves, the participants' majority showed a positive perception about themselves. It is concluded that it is important to develop health actions aimed at women in the climacteric period to disseminate information for a better understanding of the subject and thus to live sexuality in a healthy way for everyone at any age/period.

Keywords: Sexuality; Climacteric Period; Women's Health. 


\section{Introdução}

Em 2015, a Pesquisa Nacional por Amostra de Domicílios (PNAD) divulgou que a população brasileira tem cerca de 204,9 milhões de pessoas, sendo que deste quantitativo o público feminino foi responsável por $51,5 \%$ desta população. A última pesquisa realizada acerca da população residente por sexo segundo faixa etária aponta que mais de 26 milhões dos brasileiros possuem idade entre 40 a 64 anos. Desta forma, cerca de $26 \%$ das mulheres no Brasil estão na faixa etária em que ocorre o climatério ${ }^{(1-2)}$.

O climatério é definido pela transição gradual da fase reprodutiva para a não reprodutiva da vida da mulher. Durante esse período, o corpo da mulher passa por diversas mudanças fisiológicas, nas quais algumas relatam queixas de saúde relacionadas ao sistema reprodutor, porém, outras podem apresentar sintomas que variam na sua diversidade e intensidade. Pode ocorrer devido às alterações hormonais, diversas transformações biológicas, clínicas e endócrinas ${ }^{(3-4)}$.

Este período é caracterizado pelas mudanças hormonais (diminuição de estrogênio e progesterona), alterações vaginais e pela menopausa. Ocorrem também repercussões clínicas, como a síndrome climatérica, que é definida como conjunto de sinais e sintomas ${ }^{(5)}$.

Ao mesmo tempo, o climatério é um evento que ultrapassa os sintomas biológicos, pois as mulheres vivenciam experiências profundas no âmbito das relações sociais, na vida espiritual, profissional, conjugal e familiar onde estes fatores sofrem influências do contexto biológico para o seu pleno funcionamento ${ }^{(6)}$. As variáveis que mais são afetadas após a menopausa são o desejo sexual, a lubrificação vaginal, e a satisfação sexual. Mesmo assim, 65,6\% das mulheres estudadas relataram que após a menopausa, ainda pensam que a sexualidade é uma parte importante em suas vidas $^{(7)}$.

Mesmo tendo esse aspecto de negação e não aceitação, a sexualidade durante esse período pode ser vivida de forma saudável e com experiências gratificantes ${ }^{(6)}$.

A vida humana é constituída de diversas dimensões e necessidades, inclusive a sexual. A vivência da sexualidade é uma experiência humana na qual estão envolvidos vários eventos, como: afetividade, comunicação, emoção, prazer, sexo, intimidade, reprodução e etc. É vivenciada e expressada por relacionamentos, atitudes, crenças, pensamentos; e sofre influência de fatores biológicos, sociais, psicológicos, econômicos, religiosos, culturais, históricos, entre outros $^{(8)}$.

Diante do exposto, é importante destacar que, além das mudanças fisiológicas naturais que acontecem nessa fase, as mulheres também enfrentam grandes transformações que afetam de forma variada seu lado afetivo, emocional e psicossocial. Compreendendo a problematização apresentada, foi elaborada a questão norteadora acerca da situação: como as mulheres vivenciam sua sexualidade durante o período do climatério?

Dessa forma, o tema pode contribuir para a discussão e compreensão dos possíveis entraves que permeiam a vivência da sexualidade no climatério, desenvolvendo um novo olhar sobre essa fase da vida feminina.

O estudo deu voz as idosas, para compreender o significado da sua sexualidade em seu novo momento de vida, tendo como objetivo descrever como as mulheres vivenciam sua sexualidade durante o período do climatério.

\section{Método}

Trata-se de um estudo exploratório descritivo com delineamento qualitativo que foi realizado em um Centro de Saúde (CS) de Tangará da Serra no Estado de Mato Grosso - MT. Esta pesquisa foi desenvolvida após aprovação pelo Comitê de Ética em Pesquisa da Universidade do Estado de Mato Grosso (UNEMAT), sob o Certificado de Apresentação para Apreciação Ética (CAAE), n. 33471214.5.0000.5166. Todas as participantes assinaram o Termo de Consentimento Livre e Esclarecido (TCLE), por meio do qual foram informadas sobre as medidas para assegurar o anonimato e a confidencialidade sobre a origem dos dados obtidos. O presente estudo obedeceu às normas de pesquisa com seres humanos, segundo a Resolução n.ㅇ 466/2012 do Conselho Nacional de Saúde (CNS).

Para seleção das participantes foram estabelecidos os critérios de inclusão: mulheres com idade igual ou superior a 40 anos, observando 
ainda o critério de residência, devendo residir na área de abrangência da unidade, ter vida sexual ativa e que já participaram ao menos uma vez de ações de saúde realizadas na comunidade.

A coleta das informações foi realizada entre os meses de agosto e setembro de 2014. As mulheres foram abordadas enquanto aguardavam consulta na unidade. Após esse contato inicial, foram encaminhadas a um ambiente para leitura do TCLE e retirada das dúvidas quanto à pesquisa.

As entrevistas que foram previamente autorizadas pelas participantes, possibilitaram absorver de forma ampliada as informações fornecidas. As transcrições das falas ocorriam conforme eram realizadas as entrevistas, e quando novas ideias não eram acrescidas encerrou-se a coleta de dados, fazendo assim o uso da técnica de saturação. Após esse momento foi realizado o agrupamento das informações sobre as maiores dúvidas que permeavam a temática sexualidade no climatério. As participantes foram identificadas com nomes fictícios de flores, com o intuito de manter o anonimato.

Para a análise dos dados, com as informações obtidas, iniciou-se a pré-análise, os objetivos iniciais foram retomados e alguns indicadores que permeiam a interpretação final, elaborados. Como a leitura flutuante e a constituição de corpus, que buscam descobrir os núcleos de sentido compostos nas transcrições, observando a presença e frequência de unidades de significação, com atenção para valores de referência e modelos de comportamento presentes ou subjacentes no discurso ${ }^{(9)}$.

A partir da análise, emergiram três categorias empíricas: Mudanças mais significativas durante o climatério, Fatores que interferem na sexualidade e Percepção da mulher sobre si mesma.

\section{Relato de Caso}

Constitui a população deste estudo um total de 10 mulheres com idade entre 48 a 58 anos. A metade (50\%) das participantes era casada e possuíam segundo grau completo. Através da análise dos dados, emergiram três categorias que estão identificadas da seguinte maneira: Mudanças mais significativas durante o climatério,
Fatores que interferem na sexualidade e Percepção da mulher sobre si mesma.

As categorias que emergiram a partir da análise explicam um fenômeno e a articulação entre elas permitiu a construção de uma narrativa que expressa a compreensão e sentimentos vivenciados por mulheres na relação entre o climatério a e sexualidade.

\section{Mudanças mais significativas no climatério}

Nesta categoria foi possível identificar nas falas as mudanças mais significativas que ocorrem durante o climatério, descrevendo o que mudou na vida das mulheres a partir do climatério. Desta categoria emergiu três subcategorias denominadas: Mudanças no corpo, Mudanças na mente e Mudanças na sexualidade.

A subcategoria Mudanças no corpo demonstrou as modificações físicas e psicológicas que esse período trás, sendo vivenciado de forma particular por cada uma.

Os principais sintomas que aparecem são: ondas de calor na face e pescoço os famosos "fogachos", suores repentinos, insônia, sudorese noturna, cefaleias, atrofia genital, nervosismo, aumento da irritabilidade e ansiedade. Esses sintomas podem estar associados a diversos fatores, desde os níveis hormonais até a forma como a mulher vivencia estas mudanças ${ }^{(3)}$.

Os sintomas mais percebidos por elas foram os "fogachos", irregularidade menstrual, nervosismo e irritabilidade.

"Eu suei tanto nessa menopausa, o suor escorria muito, muito, é quente, mão suada [...]" Crisântemo.

"[...] eu sinto muito calor, parece que o sangue da gente fica muito agitado [...]" Lírio.

"[...] começou com o calorão, tá mais com 50 anos, muito calor, muito nervoso, a menstruação vem intercalado, tem uns 2 meses que tá assim, vem e para. Mês passado veio, esse mês já não veio [...]" Alecrim.

Algumas mulheres mencionaram que esses sintomas passaram despercebidos por elas, sendo considerado como uma fase tranquila, evidenciando que mudanças físicas e psicológicas 
aconteceram, mas foram consideradas como amadurecimento e não perda, alegando que por meio de hábitos de vida saudáveis como prática de exercícios físicos, adoção de uma dieta balanceada entre outros, esses sintomas não foram tão impactantes.

"Pra mim não mudou nada, eu sempre fui uma pessoa que toda vida me cuidei [...] eu não passei por nada disso, porque estava preparada. Eu comecei a me preparar tomando remédios homeopáticos e até hoje eu tomo. Eu nunca tive essas crises de nervosismo, de calorzão, falta de paciência, eu não passei por isso porque eu me cuidei [...]" Jasmim.

"Eu já passei por essa parte na verdade, passei muito bem, faço atividade física, sempre fiz acompanhamento com a alimentação que ajudasse e isso me levou a entrar na menopausa muito bem. Não precisei tomar hormônios, eu fiz acompanhamento médico com o ginecologista, tudo certinho, nada de medicação tudo através da alimentação e exercícios físicos. Não sinto esses sintomas de calafrios, calor, insônia, taquicardia, sudorese. Eu passei tranquilamente [...]" Azaléia.

"Pra mim não mudou muito, sabe, eu não achei muito diferença, não fico ansiosa até porque eu não deixo a chegar a esse ponto, não sou uma pessoa sedentária, eu faço exercício, eu faço natação, eu trabalho [...] Acácia.

Assim, muitas mulheres vivenciam esse período de forma assintomática ou apresentam sintomas mínimos, entendem como uma nova etapa de amadurecimento que lhes proporcionará uma experiência de vida com maior confiança e segurança, são capazes de conviver em harmonia com as modificações de seu corpo e mente ${ }^{(10)}$.

Na subcategoria Mudanças na mente, os principais sintomas psicológicos são: labilidade emocional, ansiedade, melancolia, irritabilidade, baixa autoestima, nervosismo, tristeza, depressão e dificuldade para tomar decisões ${ }^{(2)}$. Como pode ser confirmado nos depoimentos abaixo:

"[...] muita irritabilidade, nervosismo era o que sobrava pra dar e pra vender [...]" Crisântemo.
"[...] eu sou muito estressada, nervosa. [...] eu não era assim, foi depois disso que comecei ficar assim [...]" Lírio.

"[...] depois que eu entrei na menopausa, qualquer coisinha eu fico magoada, se você falar uma coisa pra mim eu já começo chorar [...] de uns tempos pra cá, se a pessoa falar qualquer coisinha pra mim eu num sei responder, eu só sei chorar, eu choro, eu tô muito sensível [...]" Copo-de-leite.

Frente a isso, o climatério gera implicações psicológicas importantes na vida da mulher. A transição do período reprodutivo para o não reprodutivo, a mudança de papéis dentro da sociedade, as mudanças metabólicas complexas, a necessidade de novas adaptações, reajustamentos interpessoais, mudanças de identidade e o contexto sócio-cultural em que ela vive influencia diretamente seu estado psicológico ${ }^{(11)}$.

$\mathrm{Na}$ subcategoria Mudanças na sexualidade, o impacto do climatério na sexualidade foi percebido pela maioria das mulheres entrevistadas como um período no qual observaram modificações importantes em sua sexualidade. A maioria percebeu que houve uma diminuição do exercício da sexualidade, e isso foi atribuído principalmente à diminuição da libido e pelas dificuldades apresentadas durante o ato sexual, como: redução da lubrificação vaginal, dispaurenia e diminuição do prazer. As falas a seguir corroboram com os autores citados acima

"Olha, mudou muito. Assim, quando a gente é novo a gente tem mais disposição pro sexo, e depois que a gente pega numa certa idade [...] diminui muito a vontade [...], não sinto muito prazer, acho que a minha vida sexual diminuiu bastante, até nos 40 anos eu era bem mais animada, mas daí já foi diminuindo e depois dos 50 anos diminuiu mais ainda" Lírio.

"[...] a gente não fica mais com aquele desejo de quando a gente é mais jovem [...] o pique já ficou baixo [...]" Orquídea.

"[...] A minha vagina fica seca, seca, eu não sinto vontade mais de fazer sexo sexo [...]" Hortênsia. 
A sexualidade abrange mais do que a capacidade física para ter relação sexual, envolve aspectos internos que abrangem a diminuição do estrogênio, tornando o epitélio do trato genital mais fino e frágil, propiciando uma secura e estreitamento vaginal com diminuição de sua rugosidade e elasticidade. A diminuição da lubrificação vaginal pode causar dor durante a relação sexual que afetará o seu relacionamento conjugal, além disso, o decréscimo gradativo dos hormônios leva a redução da libido e favorece ao desinteresse e a diminuição da atividade sexual ${ }^{(12-}$ 13).

Apesar da metade das mulheres mencionar a diminuição do desejo sexual, outras vivenciam sua sexualidade de forma plena durante esse período. Essa fase para algumas mulheres promove o aumento da libido que juntamente com a maturidade do momento contribuem para que elas exerçam sua sexualidade com mais liberdade, com um momento mais voltado para o prazer do casal e não apenas na satisfação do conjugue, conforme mostram os relatos:

"[...] eu sinto muito desejo, todo dia se meu namorado me procurar, tem [...], quando tem uma pessoa do meu lado que eu gosto e ela gosta de mim, eu me sinto bem cada vez melhor [...]" Violeta.

"[...] eu amo fazer sexo [...], pra mim, a melhor fase da minha vida sexual foi dos 40 anos até agora [...]" Crisântemo.

"Essa é uma fase da vida que a gente tá mais maduro, você faz um sexo mais diferenciado, não é aquele sexo selvagem, de paixão de adolescente. Hoje você vivencia o amor [...], hoje você vive numa harmonia [...], hoje eu estou preparada psicologicamente melhor [...], os filhos já tá criados, tenho uma condição de vida melhor [...]. Hoje eu tenho mais tempo para sexo, mais tempo pro amor, mais tempo pra tá naquele companheirismo" Azaléia.

"[...] você na fase reprodutiva tem medo de engravidar, fica naquela insegurança e depois disso, você sabe que não vai mais engravidar [...], então você tem mais liberdade [...]" Acácia.
"[...] quando você tá na vida ativa, você se tiver todo dia, você quer, só que depois de uma certa idade diminui a quantidade de vezes, mas já aumenta a qualidade, a pessoa fica com mais experiência, então tem mais qualidade [...], nessa fase é melhor por isso, não é tantas vezes, mas as poucas que têm são com qualidade, satisfaz" Acácia.

O climatério pode ser vivido de forma positiva, saudável e com autoestima. O envelhecimento e suas consequências não podem ser evitados, contudo, podem acontecer de forma tranquila e saudável, desde que as mulheres em fase climatérica estejam conscientes e preparadas para as transformações que virão a sofrer, visualizando a sexualidade como relações afetivas que proporcionam uma qualidade de vida ativa(1012-14).

Esse período também costuma acontecer paralelamente ao momento em que os filhos estão criados e saindo de casa, contribuindo assim para que o casal tenha maior liberdade sexual. Além disso, as impertinências da menstruação e a preocupação com uma gravidez deixam de existir, fazendo com que esta experiência se torne ainda mais tranquila ${ }^{(15)}$.

\section{Fatores que interferem na sexualidade}

Esta categoria demonstrou os principais fatores que interferiram no exercício da sexualidade das mulheres durante esse período. Surgindo assim, duas subcategorias denominadas, Climatério levou embora a minha juventude e o Relacionamento do casal.

A subcategoria Climatério levou embora a minha juventude, evidenciou que algumas mulheres sentiram muito a perda da beleza e o vigor da juventude.

"[...] eu me olho no espelho e tudo que eu faço em mim não adianta [...], eu quero ser, eu me arrumo, mas você vê que você não tem mais aquela aparência que você tinha antes, aquela juventude, aquela força [...]" Alecrim.

"[...] eu já fui muito bonita, bem ajeitadona, eu me olho às vezes e falo, meu Deus 
como que eu tô com a pele feia [...] como que eu tô despenlencada [...]" Lírio.

Na sociedade ocidental contemporânea, há um imperativo de um modelo de beleza baseado numa imagem construída e moldada ao longo dos tempos de uma mulher magra com características específicas. No climatério ocorre o distanciamento deste modelo de beleza, e isso contribui para que as mulheres se tornem insatisfeitas com a sua própria imagem ${ }^{(16)}$.

Logo, torna-se essencial que a mulher nessa fase considere seu corpo bonito e desejável, apesar de não ter o padrão físico estereotipado e que busque fortalecer a sua autoimagem corporal. Pois isso reflete na busca pelo amor próprio, demonstrando feminilidade e maturidade ${ }^{(17)}$.

Na subcategoria Relacionamento do casal, a maioria das mulheres entrevistadas declarou que tem um bom relacionamento, tendo cumplicidade, diálogo e compreensão por parte do companheiro.

"[...] o relacionamento com o meu esposo é muito tranquilo, a gente vem de um amadurecimento, há cumplicidade, companheirismo, amor, a gente sabe respeitar a convivência de um e do outro. Os problemas que me afetam, eu tenho problema seríssimo de saúde, faço quimioterapia ele sabe compreender isso. Por outro lado, ele tem problema coronário então eu aprendo a lidar com a deficiência dele [...]" Azaléia.

Fica evidenciado nesse relato que ambos possuem respeito e que sabem entender as dificuldades que o outro apresenta. Dessa forma, a convivência fica mais tranquila, pois não há cobrança, apenas uma cumplicidade que ultrapassa o relacionamento no dia a dia e que influencia diretamente no exercício de sua sexualidade.

É importante que o parceiro também procure elevar a autoestima de sua mulher, seja companheiro, pois isso contribui para que elas se sintam estimuladas e valorizadas, influenciando dessa forma, positivamente não só na vida cotidiana, mas também no ato sexual. Pois ao sentirem-se mais amadas e seguras, isso possibilitará melhores condições de desenvolver atividades sexuais ${ }^{(15)}$.
"[...] ele é uma pessoa que não deixa cair na rotina [...] ele já conversa, já demora mais no orgasmo, ele já espera a parceira, porque ele tem a compreensão daquilo ali, não é vup vup e acabou então ele vai espera se ele vai sentir prazer a parceira também tem que sentir então tem tudo isso aí. Tem a conversa tem o diálogo [...]" Acácia.

Por outro lado, outras mulheres citaram a falta do diálogo, do carinho, da atenção por parte do companheiro, conforme os depoimentos a seguir:

"[...] eu sinto falta de alguém pra conversar, contar historia [...] o marido chega da fazenda não conta nada, não conversa nada, então eu me sinto mais rejeitada. Fica naquela vida rotineira, você se sente rejeitada. [...]. Ele não chega assim dando abraço, um beijo em mim, não conta como que foi as coisas, não senta pra conversar [...], nessa idade eu quero mais carinho, quero dialogar. Eu quero me sentir amada não rejeitada [...]" Alecrim.

"O meu marido não é carinhoso, ele não tem nada de carinho, vai rápidão vap e vupt e acabou, com isso eu me sinto muito mal, eu não acho que isso é certo [...], nessa idade eu quero mais carinho de um para o outro, e eu sinto que ele não tem aquele carinho e quando eu vou dá carinho ele não aceita, eu acho que como ele não dá, ele também não quer receber" Hortênsia.

Esse fato pode ser explicado pelo fato do casal não possuir um relacionamento de afeto, lealdade e companheirismo. Desta forma, o relacionamento existe sem a aproximação do casal, o homem passa a enxergar sua companheira apenas na necessidade do ato sexual|(18).

Frente a isso, é necessário uma maior compreensão, afeto e diálogo conjugal. Se o relacionamento antes do climatério já não era bom, cheio de problemas, o climatério pode ser um período de explosão ou falência total. Contudo, se o casal adota a postura de enfrentar os problemas e as limitações juntos, sejam essas fisiológicas ou psicológicas decorrentes dessa transição, as dificuldades poderão ser superadas com maior tranquilidade ${ }^{(19)}$. 
As mulheres valorizam o romantismo, o carinho, atenção, a compreensão, o diálogo, o elogio. E a forma como o companheiro a percebe afetará a vivência desse momento(15).

\section{Percepção da mulher sobre si mesma}

Nesta categoria, a maioria das mulheres relatou sentimentos de satisfação consigo mesma, falou-se que houveram mudanças em suas vidas, entretanto, durante esse período, elas conseguiram fazer das mudanças um aliado, aprendendo a conviver com elas com maturidade e força.

Este dado pode ser justificado devido a este momento ser uma etapa do desenvolvimento humano e a mulher tem que aceitar as novidades que essa etapa oferece (18). Desta forma, o climatério é uma dessas fases da vida e saber compreendê-lo é uma maneira de aceitar as mudanças que acontecem neste período, conforme a fala a seguir:

"[...] a gente vai passando por transformações e tem que aceitar ela, é o percurso da nossa vida, a gente nasce, cresce, vai se transformando [...]. Somos igual a uma metamorfose, a gente se vê jovem, depois vai se modificando[...], você tem que aceitar a sua transformação [...]" Orquídea.

"[...] eu me vejo como uma pessoa mais experiente na vida, mais vivida. Hoje eu sei o que eu quero, antes eu não sabia o que queria, eu queria tanta coisa e não tinha nada [...] nessa fase você sabe o que é bom pra você [...], hoje eu faço as coisas com o pé no chão, não responsabilizo os outros pelas minhas ações [...]" Alecrim.

É fundamental que essas mulheres considerem o climatério como uma oportunidade e possibilidade de realização e renovação, usufruindo de sua experiência e maturidade. Mulheres com autoconfiança, estabilidade emocional e afetiva, uma imagem favorável de si mesma, enfim, vivenciam esse momento com mais segurança, tranquilidade e qualidade de vida. Com isso, o climatério promove perdas e ganhos que podem gerar crises, mas também possibilita conquistas e flexibilidade diante da vida ${ }^{(20-21)}$.

\section{Conclusão}

O estudo revelou que a sexualidade expressada na fase climatérica traz consigo diversas transformações no corpo da mulher, caracterizando-se as de cunho biológico, cultural e psicológico, sendo necessário um novo remodelamento pessoal e sexual durante esta etapa.

A partir dos discursos das depoentes podese perceber que, infelizmente, na sociedade ainda impera o padrão cultural, que insere a mulher na realização de papéis auto impostos, voltados a reprodução e satisfação do parceiro, além da imagem estereotipada da juventude feminina, impregnada nos dias atuais.

Por outro lado, algumas mulheres identificaram estratégias de enfrentamento mediante a fase climatérica, reconhecendo as mudanças ocorridas, e as processando de forma positiva e otimista, aceitando que as transformações biológicas fazem parte do corpo e mente, como um processo de evolução constante.

A garantia da vivencia plena sexual, em todos os ciclos biológicos é embasada através dos direitos sexuais e reprodutivos da mulher, e o climatério e suas implicações deve ser discutido e debatido constantemente nos espaços de interação em saúde, através da equipe de saúde e do enfermeiro, pautado em ações que desmitifiquem pré-conceitos, tabus, crenças, questões de gênero, autoestima e violência, dificuldades estas que permeiam a fase climatérica.

Esse estudo procurou realizar contribuições ao meio científico, acadêmico e a sociedade como um todo, frente a sensibilização e reflexão de questões que remontam a fase climatérica, acendendo por meio desse trabalho, novas discussões e dilemas enfrentados pelas mulheres, destarte, considera-se que não há pretensão de se esgotar o assunto nesta pesquisa, e sim servir de auxílio a futuras pesquisas que acendem ao tema, e auxiliando aos demais e sobretudo ao público feminino, na expressão saudável da vida sexual, redescobrindo-se integralmente em suas vicissitudes.

Desta maneira, esta pesquisa apresenta limitações, seus resultados não podem ser 
generalizados, pois apresentam particularidades que envolvem as mulheres estudadas em um contexto regional. Entretanto, apresenta subsídios para pensar a discussão do tema sexualidade no climatério de forma mais efetiva, considerando-se as necessidades, limitações e experiências vivenciadas na fase climatérica, uma vez que a sexualidade é uma dimensão fundamental de todas as etapas da vida do ser humano.

\section{Referências}

1. Instituto Brasileiro de Geografia e Estatística. Síntese de indicadores sociais: uma análise das condições de vida da população brasileira: 2016/IBGE. Coordenação de População e Indicadores Sociais. Rio de Janeiro: IBGE, 2016 [acesso em 11 mar 2017]. Disponível em: https://biblioteca.ibge.gov.br/visualizacao /livros/liv98965.pdf.

2. Ministério da Saúde (BR). População Residente por Sexo Segundo Faixa Etária Detalhada. Datasus/tabnet. 2012 [acesso em 13 nov 2017]. Disponível em: http://tabnet.datasus.gov.br/cgi/tabcgi.ex e?ibge/cnv/popbr.def.

3. Ministério da Saúde (BR). Manual de Atenção à Mulher no Climatério/Menopausa. Secretaria de Atenção à Saúde, Departamento de Ações Programáticas Estratégicas. - Brasília: Editora do Ministério da Saúde, 2008 [acesso em 09 ago 2013]. Disponível em: http://portal.saude.gov.br/port.

4. Hoffmann M, Giane KM, Canuto R, Garcez $A S$, Theodoro $H$, Rodrigues AD, Olinto MTA. Padrões alimentares de mulheres no climatério em atendimento ambulatorial no Sul do Brasil. Ciên \& Saúd Coletiva. 2015; 20(5):1565-1574.

5. Sousa JL, Zveiter M, Almeida VLM, Menezes HF, Mara G. Alves R. Educação em saúde como ferramenta à mulher no climatério: subsídios para o cuidado de enfermagem. Rev Pesq: Cuidado é Fundamental. 2011; 2616-2622.

6. Pinto $A M N$, Valadares AL, Paiva LC. Climatério e sexualidade. Rev Bras Ginecol Obstet. 2013; 2(35):93-96.

7. Melodie SI, Emilio HG. Climaterio y sexualidad. Enferm Glob. 2015; 14(40):7685.

8. Morais FRC, Penna LHG, Progianti JM. A construção do conceito da sexualidade no contexto da enfermagem. Rev Pesq: Cuidado é Fundamental. 2010; 2(3):10711079 .

9. Minayo MCS. O desafio do conhecimento: pesquisa qualitativa em saúde. 13. Ed. São Paulo: Hucitec; 2013.

10. Reis LM, et al. Influência do climatério no processo de trabalho de um hospital universitário público. Cogitare Enfermagem. 2011; 2(16):232-239.

11. Pitelli JB. Sexualidade no climatério: influencias psicológicas e socioculturais. Rev Bras Sexualidad Humana. 1997; 2(8):238-253.

12. Saraiva RJ, Rosas AMMTF, Valente GSC. A intersubjetividade entre enfermeiros e idosos sobre sexualidade no contexto da consulta de enfermagem. Rev Enferm Atual. 2017; 83.

13. Cabral PUL, et al. Influência dos sintomas climatéricos sobre a função sexual de mulheres de meia-idade. Rev Bras Ginecol Obstet. 2012; 7(32):329-334.

14. Frugoli A, Júnior CAOM. A sexualidade na terceira idade na percepção de um grupo de idosas e indicações para a educação sexual. Arq Ciênc Saúde UNIPAR. 2011; 1(15):85-93. 
15. Silva TB, Borges MMMC. Sexualidade após a menopausa: situações vivenciadas pela mulher. Revista Enfermagem Integrada. 2012 2(5):1018-1032.

16. Zanotelli SS. Vivências de mulheres acerca do climatério em uma unidade de saúde da família [Dissertação]. Santa Maria: Universidade Federal de Santa Maria, 2010.

17. Valença CN, Filho JMN, Germano RM. Mulher no climatério: reflexões sobre desejo sexual, beleza e feminilidade. Saúde Soc. 2010; 2(19):273-285.

18. Lucena CT, et al. Percepções de mulheres no climatério sobre sua a sexualidade. Revista da Universidade Vale do Rio Verde. 2014; 1(12):28-37.

19. Oliveira DM, Jesus MCP, Mereghi MAB. Climatério e sexualidade: a compreensão dessa interface por mulheres assistidas em grupo. Text Context Enferm. 2008; 3(17):519-526.

20. Schmalfuss J.M et.al. Percepções e vivências das mulheres acerca do climatério. Rev Enferm UFPE On-line. 2014; 8(10):3039-46.

21. Zampieri MFM; et.al. O processo de viver e ser saudável das mulheres no climatério. Rev Esc Enfem Anna Nery. 2009; 2(13):305-312. 